\title{
Paracervical block with $1 \%$ lidocaine for pain control during intrauterine device insertion: a prospective, single-blinded, controlled study
}

\section{Derya Akdağ Cırık ${ }^{1}$, Elif A. Taşkın²*, Alper Tuğlu ${ }^{3}$, Arzu Sümer Ortaç ${ }^{3}$ Ömer Dai ${ }^{4}$}

\author{
${ }^{1}$ Etlik Zübeyde Hanım Maternity Hospital, Department of Obstetrics and Gynecology, Ankara, Turkey \\ ${ }^{2}$ Ankara Education and Research Hospital, Department of Obstetrics and Gynecology, Ankara, Turkey \\ ${ }^{3}$ Samsun Maternity Hospital, Department of Obstetrics and Gynecology, Samsun, Turkey \\ ${ }^{4}$ Ankara University Faculty of Medicine, Department of Obstetrics and Gynecology, Ankara, Turkey
}

Received: 28 May 2013

Accepted: 15 June 2013

\author{
*Correspondence: \\ Dr. Elif A. Taşkın \\ E-mail: eclamptic2000@yahoo.com
}

(C) 2013 Crrık DA et al. This is an open-access article distributed under the terms of the Creative Commons Attribution Non-Commercial License, which permits unrestricted non-commercial use, distribution, and reproduction in any medium, provided the original work is properly cited.

\begin{abstract}
In this prospective controlled study we aimed to investigate efficacy of paracervical block with $1 \%$ Lidocaine for pain control and demographic variables which may affect pain perception during intrauterine device insertion in Turkish women. Data from 95 women assigned to paracervical block $(n=34)$, placebo $(n=30)$ and no treatment $(n=31)$ arms and asked to grade the pain level they felt during tenaculum placement, intrauterine device insertion and 5 minutes after the procedure using a visual pain scale. Demographic variables were also recorded. Pain scores were found to be lower in paracervical block group when compared to other 2 groups during tenaculum placement $(\mathrm{p}=0.00)$, intrauterine device insertion $(\mathrm{p}=0.00)$ and 5 minutes after the procedure $(\mathrm{p}=0.00)$. Level of pain was unrelated to mode of previous deliveries and current breastfeeding. Paracervical block is an easy, safe and effective way of pain control during intrauterine device insertion. Lack of vaginal birth history is not a reason to draw back from intrauterine device use.
\end{abstract}

Keywords: Intrauterine device, Pain, Lidocaine, Paracervical block

\section{INTRODUCTION}

After its first use in 1980, Copper T380 intrauterine device (IUD) gained popularity because of its ease of use, safety and efficacy. Approximately $5.5-20 \%$ of $15-44$ years old women in need of contraception prefer IUD in different developed countries. ${ }^{1}$ In Turkey, IUD is the most commonly preferred method among modern contraceptive methods. Sixteen point nine percent of modern contraceptive method users $(46 \%$ of reproductive aged women) prefer IUD in our country. ${ }^{2}$ Major shortcoming of the method is pain during insertion.

Paracervical block, widely used for interventions to uterus in office setting, can be an option for pain control during IUD insertion.
In this randomized controlled study we investigated demographic variables which may affect pain perception and efficacy of paracervical block for pain control during IUD insertion in Turkish women.

\section{METHODS}

This randomized placebo-controlled study was conducted in Samsun Maternity Hospital, Turkey. Ninety five women between 18-45 years of age presented to the Family Planning Unit for IUD insertion between December 2012 and March 2013 meeting inclusion criteria were enrolled to the study after written informed consents were obtained. Institutional Ethical Board approved the study. 
Women with Lidocaine or copper allergy, uterine Müllerian anomalies, cervicitis, uterus bigger than 3 months of gestation, fibroids or polyps were not enrolled. Also women who had an analgesic medication within 6 hours of the procedure or any drug for cervical dilatation like misoprostol, pelvic inflammatory disease history within last three months or pregnancy within 6 weeks were excluded. Participants were randomized into 3 groups: First group of patients received $10 \mathrm{ml} \mathrm{1 \%} \mathrm{Lidocaine} \mathrm{for}$ paracervical block, second group received $10 \mathrm{~mm} 0.9 \%$ $\mathrm{NaCl}$ solution paracervically injected as placebo and third group received no analgesia before IUD insertion. Five $\mathrm{ml}$ of either $1 \%$ lidocaine or $0.9 \% \mathrm{NaCl}$ solution was injected at 3 o'clock and other $5 \mathrm{ml}$ at 9 o'clock position of cervix 5 minutes before IUD insertion.

All participants were informed about the procedure of the IUD insertion and asked for their current pain level during the steps of the procedure by using visual pain scale. No pain was graded as 0 and the worst pain ever felt was 10 in this scale. Patients specified their degree of pain by marking a mark on this scale at 3 points during the IUD insertion procedure. These steps were immediately after tenaculum placement, immediately after IUD insertion and 5 minutes after procedure.

Following routine pelvic examination, speculum was placed into vagina, and cervix is cleaned with $10 \%$ iodine solution. Later we injected 1\% lidocaine for paracervical block in Group1, or saline for placebo into the ectocervix in Group 2. We gave no analgesic medication to the third group of women. After 5 minutes waiting, cervix is hold with a tenaculum and the IUD is applied in the standard method. The family planning clinic care providers are the senior resident and gynecologists and they were not blinded. The socio-demographic data were collected by interview at the beginning of the procedure and the data related to the procedure including the need for cervical dilatation and the side effects observed during the IUD insertion were noted by the physician at the end.

Statistical analysis was performed with SPSS version 13.0 for Windows (SPSS, Inc., Chicago). Demographical variables, complication rates and pain scores were compared with either Anova test or Kruskal-Wallis test. The Chi-square tests $\left(\mathrm{x}^{2}\right)$ were used to compare frequencies of categorical variables. Significance level was set a $P$ value $<0.05$. Tukey Correlation analysis was done with Spearman's correlation test.

\section{RESULTS}

Totally 95 patients were enrolled in the study. The most common reason which made the patients ineligible for participation to study was current cervicitis or taking medication within 6 hours of study. There was 1 patient who declined participation because she was afraid of injections. All groups were similar in terms of tested demographic variables (Table 1). There were also no differences with regard to history of surgical abortion, cesarean section, excision of transformation zone, or current breastfeeding.

Table 1: Socio-demographic data of the patients.

\begin{tabular}{|c|c|c|c|c|}
\hline Patient Characteristics & $\begin{array}{l}\text { Paracervical } \\
\text { block }(\mathbf{n}=\mathbf{3 4})\end{array}$ & $\begin{array}{l}\text { Saline } \\
(\mathbf{n}=\mathbf{3 0})\end{array}$ & $\begin{array}{l}\text { No Treatment } \\
(\mathrm{n}=\mathbf{3 1})\end{array}$ & $P$ value \\
\hline Age (median, range) & $28.5(19-42)$ & $27(20-43)$ & $30(15-44)$ & 0.19 \\
\hline BMI (median, range) & $25.9(17-34.7)$ & $26(15.7-365)$ & $26.5(22-30.8)$ & 0.20 \\
\hline $\begin{array}{l}\text { Education }(\mathrm{n}) \\
\text { None } \\
\text { Primary school } \\
\text { Secondary school } \\
\text { High school } \\
\text { Licence }\end{array}$ & $\begin{array}{l}3(8.8 \%) \\
20(58.8 \%) \\
3(8.8 \%) \\
4(11.8 \%) \\
4(11.8 \%)\end{array}$ & $\begin{array}{l}1(3.3 \%) \\
14(46.7 \%) \\
10(33.3 \%) \\
4(13.3 \%) \\
1(3.3 \%)\end{array}$ & $\begin{array}{l}1(3.2 \%) \\
19(61.3 \%) \\
2(6.5 \%) \\
6(19.4 \%) \\
3(9.7 \%)\end{array}$ & 0.12 \\
\hline $\begin{array}{l}\text { History of surgical abortion } \\
\text { No } \\
\text { Yes }\end{array}$ & $\begin{array}{l}29(85.3 \%) \\
5(14.7 \%)\end{array}$ & $\begin{array}{l}27(90 \%) \\
3(10 \%)\end{array}$ & $\begin{array}{l}27(87.1 \%) \\
4(12.9 \%)\end{array}$ & 0.85 \\
\hline $\begin{array}{l}\text { Currently breastfeeding } \\
\text { No } \\
\text { Yes }\end{array}$ & $\begin{array}{l}24(70.6) \\
12(35,3 \%)\end{array}$ & $\begin{array}{l}18(60 \%) \\
12(40 \%)\end{array}$ & $\begin{array}{l}23(68.4 \%) \\
18(58,1 \%)\end{array}$ & 0.15 \\
\hline $\begin{array}{l}\text { History of Cesarean Section } \\
\text { No } \\
\text { Yes }\end{array}$ & $\begin{array}{l}24(70.6 \%) \\
10(29.4 \%)\end{array}$ & $\begin{array}{l}18(60 \%) \\
12(40 \%)\end{array}$ & $\begin{array}{r}23(68.4 \%) \\
8(25.8 \%)\end{array}$ & 0.46 \\
\hline $\begin{array}{l}\text { History of LEEP } \\
\text { No } \\
\text { Yes }\end{array}$ & $\begin{array}{c}32(94.1 \%) \\
2(5.9 \%)\end{array}$ & $\begin{array}{c}30(100 \%) \\
0(0 \%)\end{array}$ & $\begin{array}{c}31(100 \%) \\
0(0 \%)\end{array}$ & 0.16 \\
\hline
\end{tabular}

BMI: Body mass index. LEEP: loop electrosurgical excision procedure. 
The complications were all similar in three groups. There were 5 patients who had vasovagal syncope, one in the paracervical group, 2 in saline group and 2 were in the no treatment group $(\mathrm{p}=0.36)$. Vasovagal symptoms like nausea and vomiting were also similar between groups. $(\mathrm{p}=0.06)$ There were no bleeding and uterine perforation in any of the patients in the study. Only 2 patients in each group need dilatation for IUD insertion.

Pain scores were found to be unrelated to advanced age $(\mathrm{p}=0.83)$, high parity $(\mathrm{p}=0.89)$ and body mass index (BMI) $(\mathrm{p}=0.33)$.

In this study there was only one nulliparous patient who undergone IUD insertion. So we could not compare the pain scores of nulliparous and multiparous patients. Instead, we compared pain scores of the patients who had Cesarean section(s) but no vaginal birth with patients who had at least one vaginal birth (Table 2). The median of pain scores was 5 (range 0-7) in the group of patients who had vaginal birth and 5.5 (range 0-7) in the group of patients who had only Cesarean section. Likewise we compared median pain scores with tenaculum placement and 5 minutes after insertion, we found no difference between two groups.

A significant number of patients (42 out of 95) in our study were currently breastfeeding. We analyzed if there is any effect of breastfeeding and found that median pain scores with IUD insertion were the same (5, range $0-7$ ) for both the breastfeeding and not breastfeeding patients (Table 2).

Table 2: Pain scores.

\begin{tabular}{|llll|}
\hline & $\begin{array}{l}\text { Tenaculum } \\
\text { (median, } \\
\text { range) }\end{array}$ & $\begin{array}{l}\text { Intrauterine } \\
\text { Device } \\
\text { Insertion } \\
\text { (median, } \\
\text { range) }\end{array}$ & $\begin{array}{l}5 \text { minute } \\
\text { after } \\
\text { (median, } \\
\text { range) }\end{array}$ \\
\hline $\begin{array}{l}\text { Paracervical } \\
\text { block (n:34) } \\
\begin{array}{l}\text { Placebo } \\
\text { (n:30) }\end{array}\end{array}$ & $4(0-6)$ & $2(0-5)$ & $1(0-4)$ \\
$\begin{array}{l}\text { No treatment } \\
\text { (n:31) }\end{array}$ & $7(5-8)$ & $6(2-7)$ & $4(1-6)$ \\
P values & 0.00 & 0.00 & $4(1-6)$ \\
\hline $\begin{array}{l}\text { Breastfeeding } \\
\text { (n:42) }\end{array}$ & $6(0-8)$ & $5(0-7)$ & $3(0-6)$ \\
$\begin{array}{l}\text { Not } \\
\text { breastfeeding } \\
\text { (n:53) }\end{array}$ & $6(1-9)$ & $5(0-7)$ & $3(0-6)$ \\
P values & 0.63 & 0.63 & 0.37 \\
\hline $\begin{array}{l}\text { Vaginal } \\
\text { delivery }(\geq 1) \\
\text { No vaginal } \\
\text { delivery }\end{array}$ & $6(1-8)$ & $5.5(0-7)$ & $3(0-6)$ \\
P values & 0.54 & $5(0-7)$ & $3(0-6)$ \\
\hline
\end{tabular}

As primary outcome of this study, pain scores during IUD insertion is found to differ significantly among 3 groups (Table 2). The median pain scores were found to be 2 (range 0-5), 6 (range 2-7) and 6 (range 3-7), respectively, in paracervical block, placebo and no treatment groups. Similarly, median pain scores 5 minutes after IUD insertion were found to differ significantly among 3 groups. $(\mathrm{p}=0.00)$ Median pain scores in paracervical group was 1 (range $0-4$ ), on the other hand 4 (range 1-6) in other 2 groups. When we analyze the pain scores felt immediately after tenaculum application, pain scores of the patients in the paracervical block group were found statistically lower than other 2 groups $(\mathrm{p}=0,00)$. The median pain score was 4 (range 0 6 ) in the study group, whereas it was 7 (range 4-9) in the saline group and 7 (range 5-8) in the no treatment group.

\section{DISCUSSION}

Major factor limiting IUD use seems to be fear of pain related to insertion procedure. In order to minimize this pain, efficacy of analgesics (both paracervical and cervical applications of analgesics, or oral medications) were studied in limited number of studies previously.

Although paracervical block is widely used for pain control in surgical abortion and labor, there is only one study on this issue in the literature. Mody et al. investigated effectiveness of paracervical injection of 10 $\mathrm{ml}$ of $1 \%$ lidocaine and found pain scores to be less in paracervical block group (24 $\mathrm{mm}$, range 0-99 $\mathrm{mm}$ ) when compared to no local analgesia group (62 mm, range 2-89 $\mathrm{mm})$, although difference was not statistically significant probably due to high standard deviations. ${ }^{3}$

Hubacher et al. evaluated effectiveness of oral ibuprofen for pain control during IUD insertion. They randomized 2019 women to drug and placebo groups and found out that oral $400 \mathrm{mg}$ ibuprofen taken 45 minutes before IUD insertion to be ineffective to reduce pain caused by IUD insertion. $^{4}$

Allen et al. reviewed all randomized controlled studies on pain control in IUD insertion, and found both nonsteroidal analgesic and misoprostol use ineffective. ${ }^{5}$ Similarly buccal and vaginal misoprostol application to nulliparous women before IUD insertion was reported to be ineffective for pain control and also associated with side effects. ${ }^{6,7,8}$

McNicholas et al. randomized 199 women to either Lidocaine or placebo gel groups and applied gels to both ectocervix and endocervix (via catheter). ${ }^{9}$ Tenaculum and IUD were applied 3 minutes after the gel is used, and pain scores were found to be statistically similar. Short waiting time in this study may be speculated to limit diffusion of the gel to the sensory nerves. Similarly Maguire et al. found intracervical Lidocaine gel to be ineffective to decrease pain during IUD insertion in 
their randomized controlled study conducted on 200 participants. ${ }^{10}$

In this study we randomized a total of 95 women to paracervical lidocaine injection, placebo and no treatment arms before IUD insertion and compared pain perception during tenaculum and IUD application and 5 minutes after the procedure (Table 2).

We preferred direct injection of lidocaine and placebo to 3 and 9 o'clock positions of the cervix where the cervical neuronal plexus is localized and waited for 5 minutes before any intervention.

Results of this study demonstrated significantly lower pain perception in paracervical block group when compared to placebo and no treatment groups (Table 2). Pain scores in paracervical block group of our study are similar to scores reported by Mody et al. ${ }^{3}$ and higher than scores (of multiparous women) reported by Maguire et al. ${ }^{10}$ Especially tenaculum application cause higher pain scores in all 3 groups in our study when compared to studies above mentioned. This may be a result of concentration of the women to pain due to our informing speech about the study just before the procedure. Paracervical block seems to decrease post procedure pain also. Univariate analyses have shown that pain scores were not related to advanced patient age $(\mathrm{p}=0.83)$, high parity $(\mathrm{p}=0.89), \mathrm{BMI}(\mathrm{p}=0.33)$, current breastfeeding or history of vaginal delivery (Table 2). Different from our results, some researchers previously reported women above 30 years of age to have higher pain scores, ${ }^{4}$ women with higher gravidity to have lower pain scores, ${ }^{3}$ women with lower BMI to have higher pain scores $^{3}$ and breastfeeding women to have lower pain scores. ${ }^{11}$

Previously Hubacher et al. reported nulliparity and time since last vaginal birth shorter than 3 months to be associated with higher pain scores during IUD insertion ${ }^{4}$ some other studies also support the finding of higher pain scores in nulliparous women. ${ }^{6,10}$ As we have only 1 nulliparous participant, we could not analyze effect of nulliparity on pain perception. Instead, we compared multiparous women without history of vaginal delivery, who can resemble nulliparous women in this context, and women who had at least one vaginal delivery, and did not find any difference in terms of pain perception in any step of intervention (Table 2). As a shortcoming, we did not question time since last vaginal delivery and analyze its effect on pain scores.

Copper T IUD is the single kind of IUDs provides free of charge in state hospitals and Family Health Centers in our country. That's why it is the most widely known and used type, and we conducted this study on only this type of IUD. Another study comparing pain scores during insertions of different kinds of IUDs may also be beneficial.

As far as we know, this study is the only prospective randomized placebo controlled study on the pain control during IUD insertion with the paracervical block which is found to decrease pain perception when compared to placebo and no treatment groups. Lack of vaginal birth history is not a reason to draw back from IUD use. We did not identify any subgroup of women who experience pain more prominent than others.

Widespread use of IUDs which is an effective, safe and long-term way of contraception should be encouraged worldwide. Prejudices and fear of pain, especially in nulliparous and adolescent women should be overcome. As NSAIDs were previously shown to be ineffective, paracervical block performed safely and easily by trained care providers (e.g. gynecologists, family physicians, general practitioners, nurses, or midwives) can be used to reduce pain perceived during IUD insertion.

\section{Funding: None}

Conflict of interest: None declared

Ethical approval: The study was approved by the Institutional Ethical Board

\section{REFERENCES}

1. Mosher WD, Jones J. Use of contraception in the United States: 1982- 2008. Vital Health Stat 2010; 29:1-44.

2. Turkey demographic and health survey 2008, Hacettepe University Institute of Population Studies in collaboration with Turkish Republic Ministry of Health and Prime Ministry Undersecretary of State Planning Organization.

3. Mody SK, Kiley J, Rademaker A, et al. Pain control for intrauterine device insertion: a randomized trial of $1 \%$ lidocaine paracervical block. Contraception 2012;86:704-9.

4. Hubacher D, Reyes V, Lillo S, et al. Pain from copper intrauterine device insertion: randomized trial of prophylactic ibuprofen. Am J Obstet Gynecol 2006;195:1272-7.

5. Allen RH, Bartz D, Grimes DA, et al. Interventions for pain with intrauterine device insertion. Cochrane Database Syst Rev 2009;3:CD007373.

6. Dijkhuizen K, Dekkers OM, Holleboom CA, et al. Vaginal misoprostol prior to insertion of an intrauterine device: an RCT. Hum Reprod 2011; 26:323-9.

7. Edelman AB, Schaefer E, Olson A, et al. Effects of prophylactic misoprostol administration prior to intrauterine device insertion in nulliparous women. Contraception 2011;84:234-9.

8. Swenson C, Turok DK, Ward K, et al. Selfadministered misoprostol or placebo before intrauterine device insertion in nulliparous women: a randomized controlled trial. Obstet Gynecol 2012; 120:341-7.

9. McNicholas CP, Madden T, Zhao Q, et al. Cervical lidocaine for IUD insertional pain: a randomized 
controlled trial. Am J Obstet Gynecol 2012;207: 384.e1-6.

10. Maguire K, Davis A, Rosario Tejeda L, Westhoff C. Intracervical lidocaine gel for intrauterine device insertion: a randomized controlled trial. Contraception 2012;86:214-9.
11. Chi IC, Wilkens LR, Champion CB, et al. Insertional pain and other IUD insertion-related rare events for breastfeeding and non-breastfeeding women-a decade's experience in developing countries. Adv Contracept 1989;5:101-19.

DOI: $10.5455 / 2320-1770 . i j r \operatorname{cog} 20130902$

Cite this article as: Cırık DA, Taşkın EA, Tuğlu A, Ortaç AS, Dai O. Paracervical block with $1 \%$ lidocaine for pain control during intrauterine device insertion: a prospective, single-blinded, controlled study. Int J Reprod Contracept Obstet Gynecol 2013;2:263-7. 